\title{
Uterine perforation by the levonorgestrel-releasing intrauterine device: case report
}

\author{
Erik Lajtman • Peter Uharček • Miloš Mlynček
}

Received: 29 March 2008/Accepted: 9 June 2008 / Published online: 5 July 2008

(C) Springer-Verlag 2008

\begin{abstract}
The authors demonstrate a case report of the uterine perforation by the levonorgestrel-releasing intrauterine device (LNG-IUD) in a 33-year-old asymptomatic woman after an 18-month period after insertion. The device was not localized in utero during routine control with transvaginal sonography. After abdominal radiography examination the device was removed by laparoscopy. The possibilities of transuterine migration of IUD are discussed.
\end{abstract}

Keywords Uterine perforation · Intrauterine device

\section{Introduction}

An intrauterine device (IUD) is one of the commonly used forms of contraception. A half of users are in China [1]. The levonorgestrel medicated IUD (LNG-IUD) marketed as Mirena $^{\circledR}$ (Bayer Schering Pharma, Germany) was introduced in Slovakia in 1999. The local effect of levonorgestrel in the uterine cavity, sperm mobility inhibition, changes of endometrium structure, and cervical mucus changes are specific effects of Mirena ${ }^{\circledR}$. The LNG-IUD reduces menstrual blood flow and is potential prevention of endometrial hyperplasia $[2,3]$.

A serious complication associated with the insertion of IUD is uterine perforation. The risk of perforation ranges from 0 to 1.3 per 1,000 insertions [4]. Several cases of LNGIUD-related uterine perforation have been reported [5-8].

E. Lajtman $\cdot$ P. Uharček $(\triangle) \cdot$ M. Mlynček

Department of Obstetrics and Gynecology, Faculty Hospital Nitra,

Špitálska 6,

94901 Nitra, Slovak Republic

e-mail: uharcek@hotmail.com
We describe the first case of asymptomatic uterine perforation by LNG-IUD in Slovakia.

\section{Case report}

A 33-year-old woman, gravida 2, para 2, with history of regular menstrual cycles after discussion with her physician opted for an levonorgestrel-releasing intrauterine device (Mirena ${ }^{\circledR}$, Bayer Schering Pharma, Germany) for contraception. The device was inserted 12 weeks after her last delivery. The woman was not lactating at the time of a insertion. The procedure of the insertion was reported as uneventful. Routine transvaginal sonogram (TVS) performed immediately after the insertion showed LNG-IUD in uterine cavity. She was amenorrheic after insertion. During routine control after 18 months TVS failed to demonstrate the device in the uterus. An antero-posterior radiograph of the abdomen confirmed the diagnosis of a misplaced intra-abdominal IUD. The woman had no history of abdominal pain or irregular uterine bleeding during the last 18 months. Laparoscopy for IUD removal was scheduled. During laparoscopy uterus and adnexae appeared normal. The perforation site on the uterine wall was not identified. IUD was observed in the omentum encased in mild peritoneal adhesions (Fig. 1). A simple laparoscopic procedure with the removing of IUD was accomplished. The patient was discharged $24 \mathrm{~h}$ after laparoscopy.

\section{Discussion}

Uterine perforation in IUD users is not a common complication. The estimated incidence is 2.6 per 1,000 insertions in Netherlands [9]. Our case is the first reported in Slovakia. 


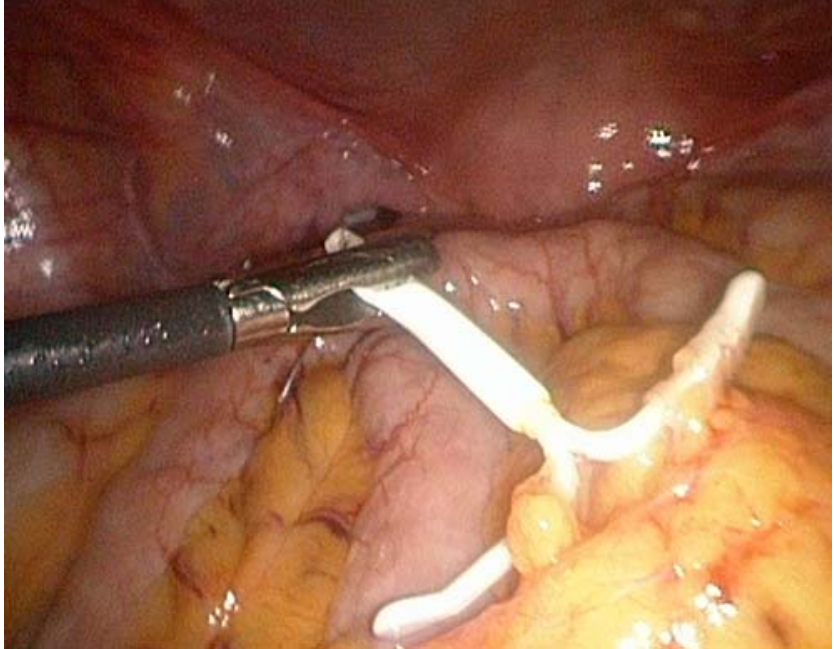

Fig. 1 IUD

The hypothesis of uterine perforation during IUD insertion is perforation of the uterine wall by the sound or by the inserter tube or by IUD itself. Another mechanism might be partial perforation at the time of insertion, resulting in uterine contractions causing complete perforation [4]. One reason for perforation is the failure to establish the size and orientation of the uterus by careful pelvic examination. This is particularly important where there is sharp ante- or retroflexion of the uterus, and where it is not straightened with traction using a tenaculum prior to insertion [5]. Complexity of the insertion procedure of the Mirena LNG-IUS might have played a role in the (partial) perforation of the fundus: as the arms of the IUD are retracted in the tube, creating a narrow protruding element, pushing the IUS out instead of retracting the tube would increase the risk of perforation. Abdominal pain is a common symptom [9].

The insertion during lactation even beyond 6 weeks after delivery is an important risk factor for perforation and is associated with less pain. Such cases may therefore easily pass unnoticed [10].

Studies have shown that cervical traction in a caudal direction reduces the median uterocervical angle, from $75^{\circ}$ to $10^{\circ}$ and moderate cervical traction straightens the uterus, and the routine use of a tenaculum theoretically should make insertion of an IUD safer. A prerequisite, however, is that traction should be applied until the insertion of the IUD has been completed. In addition, clinical experience shows that access to the uterus, and straightening of the utero-cervical axis, is facilitated by using the lithotomy position which should be recommended for all IUD/IUS insertions [11].

The manufacturer of the LNG-IUD recommends that postpartum insertions should be postponed until 8-weeks postdelivery. IUD insertion immediately after a first trimester abortion seems to be both safe and practical [12].

A routine check-up 6 weeks after insertion of a LNGIUD including TVS is recommended [13].

Intraperitoneal dislocated LNG-IUD resulted in plasma levonorgestrel levels ten times higher than the plasma level of levonorgestrel observed with LNG-IUD placed in uterus. High plasma levonorgestrel level supresses ovulation. When pregnancy is desired a misplaced LNG-IUD should be removed. There is a consensus for removal of a perforated IUD mainly because of the potential for adhesion formation [8]. The development of peritoneal adhesions as a response to a non-irritating plastic-made foreign body was described by Echenberg and Ledger [14]. Mirena ${ }^{\circledR}$ is covered by a polydimethylsiloxane membrane. The effect of high levonorgestrel concentrations on the cytoplasm was identified in the submesothelial cells. The pseudodecidual changes also known as ectopic peritoneal decidua were described as developing solely in relation to pregnancy when there were found in the sites such as the submesothelial stroma of the uterus, the uterine ligaments, adnexae, appendix, and omentum [15]. The effects of progestogens on the formation of peritoneal adhesions are unclear. Progesterone has anti-inflammatory and immunosuppressive effects that could play a role in the prevention of peritoneal adhesion formation [15].

Laparoscopy is the method of choice for removal of the displaced IUD. From the point of risks of adhesion formation after the laparotomy in the case with encapsulated IUD by the firm adhesions it may be safer to leave a misplaced device in place than to remove it by laparotomy. Conversion of laparoscopy to laparotomy is indicated only on the patients with the serious complications during laparoscopy.

\section{References}

1. Dennis J, Hampton N (2002) IUDs: which devices? J Fam Plan Reprod Heath Care 28:61-68

2. Masters T, Miskry T, Lowe D et al (1997) Report of ectopic pregnancies associated with the levonorgestrel intrauterine system. Br J Fam Plan 23:25-26

3. Raudaskoski T, Tapanainen J, Tomas E et al (2002) Intrauterine 10 microg and 20 microg levonorgestrel systems in postmenopausal women receiving oral estrogen replacement therapy: clinical, endometrial and metabolic response. $\mathrm{Br} \mathrm{J}$ Obstet Gynaecol 109:136-144

4. Andersson K, Ryde-Blomqvist E, Lindell K et al (1998) Perforation with intrauterine devices. Report from a Swedish survey. Contraception 57:251-255

5. Tatum HJ, Connell EB (1989) Intrauterine devices. In: Filshie M, Guillebaud J (eds) Contraception: science and practice. Butterworths, London, pp 144-171

6. Ng Kee Kwong F, Rai H, Mayne C (2002) Ectopic pregnancy with a translocated MirenaOे intrauterine system. J Fam Plan Reprod Health Care 28:95-96 
7. Bobrow C, Cooling H, Bisson D (2000) Amenorrhoea despite displaced levonorgestrel intra-uterine system. Br J Fam Plan 26: 105-106

8. Haimov-Kochman R, Doviner V, Amsalem H et al (2003) Intraperitoneal levonorgestrel-releasing intrauterine device following uterine perforation: the role progestins in adhesion formation. Hum Reprod 18:990-993

9. Van Houdenhoven K, van Kaam KJAF, van Grootheest AC et al (2006) Uterine perforation in women using a levonorgestrelreleasing intrauterine system. Contraception 73:257-260

10. Chi IC, Potts M, Wilkens L et al (1989) Performance of the TCu380A device in breastfeeding and non-breastfeeding women. Contraception 39:603-618
11. Johnson N, Bromham DR (1991) Effect of cervical traction with a tenaculum on the uterocervical angle. $\mathrm{Br} \mathrm{J}$ Obstet Gynaecol 98:309-312

12. Grimes D, Schulz K, Stanwood N (2002) Immediate postabortal insertion of intrauterine devices. Cochrane Database Syst Rev 5: $121-126$

13. Harrison-Woolrych M, Ashton J, Coulter D (2003) Uterine perforation on intrauterine device insertion: is the incidence higher than previously reported? Contraception 67:53-56

14. Echenberg R, Ledger WJ (1968) Peritoneal response to polyethylene foreign bodies. Obstet Gynecol 31:795-798

15. Maurer JH, Bonaventura LM (1983) The effect of aqueous progesterone on operative adhesion formation. Fertil Steril 39:485-489 